\title{
Lessons for Diabetes Care from Kahlil Gibran's The Prophet
}

\author{
Sanjay Kalra ${ }^{1}$ Gagan Priya ${ }^{2}$ Sundeep Ruder ${ }^{3}$ \\ ${ }^{1}$ Department of Endocrinology, Bharti Hospital, Karnal, India \\ ${ }^{2}$ Department of Endocrinology, Fortis Hospital, Mohali, India \\ 3Department of Endocrinology and Metabolism, Charlotte Maxeke \\ Johannesburg Academic Hospital, Johannesburg, South Africa \\ J Soc Health Diab 2019;7:11-15
}

\begin{abstract}
Address for correspondence Sanjay Kalra, DM, MD, Department of Endocrinology, Bharti Hospital, Karnal 132001, India (e-mail: brideknl@gmail.com).
\end{abstract}
Abstract
Keywords
- biopsychosocial model
- patient-centered care
- psychosocial aspects of diabetes

Khalil Gibran's book The Prophet (1923) shares the conversations of a preacher, Almustafa, as he prepares to leave the city of Orphalese, where he spent 12 years. A collection of prose poetry fables continues to inspire people from all walks of life and remains as relevant as when it was written. This opinion piece uses curated verses from The Prophet to highlight the relevance of Gibran's timeless wisdom to modern diabetes care. It attempts to extract core lessons and present in a contemporary way for a modern health care professional to effect on and use.

\section{Introduction}

Khalil Gibran (1883-1931), the famous Lebanese philosopher, is known for his poetic works. His writings, translated and read across the globe, have influenced thinkers across cultures and generations. His book The Prophet (1923) is famed for its sempiternal value. The Prophet shares the words of a preacher, Almustafa, as he prepares to leave the city of Orphalese, where he spent 12 years. While he rejoices at the arrival of the much-awaited ship that would take him to the isle of his birth, there is also the sadness and ache of leaving everything and everyone behind. Before his departure, Almitra, the seeress, urges him to speak of what has been shown to him of that between birth and death. The book, a collection of prose poetry fables, describes the conversation of Almustafa with the people of Orphalese. ${ }^{1}$ The Prophet continues to inspire people from all walks of life and remains as relevant as when it was written.

This opinion piece uses curated verses from The Prophet to highlight the relevance of Gibran's timeless wisdom to modern diabetes care. It attempts to extract core lessons and presents in a contemporary way for a modern health care professional to effect on and use.

Gibran writes:

"The soul walks not upon a line, neither does it grow like a reed

... The soul unfolds itself like a lotus of countless petals." On Self-Knowledge: Ch. 17, p. 79
Those engaged in diabetes care are acutely aware of how little we understand about this chronic multisystemic disease. Diabetes is a heterogeneous disorder, and the more we strive to understand it, the more it perplexes us. This way, diabetes can be compared with the soul. Its pathophysiology is complex and multifactorial. It does not follow a clear well-defined or predictable course, and every individual is unique. Over the decades, understanding of this disorder has unfolded unto the medical field like petals of a lotus. This evolution continues to bring forth several breakthroughs in management.

Understanding diabetes is an act of constant learning. One can only marvel at the mysteries of normal physiology, as researchers attempt to find ways to overcome the multiple pathophysiological defects involved in diabetes and its comorbidities. The clinician constantly learns from his/her interaction with persons living with diabetes, each of whom is a lesson in themselves. A key lesson here is that knowledge must be accompanied by humility. This is true wisdom. As we learn more, there will still be more to learn, knowing this we do not become complacent in our work.

\section{Diabetes Care Professional}

\section{Work Ethics}

In its Chapter 7, a ploughman asks: "Speak to us of work." The Prophet's answer is as relevant for us as it is for the ploughman. In fact, The Prophet seems to address diabetes care professionals directly. In his verses, he highlights the importance of work:

C2019 Novo Nordisk Education

License terms

Foundation
December 22, 2018

accepted

December 26, 2018
DOI https://doi.org/

10.1055/s-0039-1683469

ISSN 2321-0656. 
"You work that you may keep pace with the earth and soul of the earth."

On Work: Ch. 7, p. 37

A suggestion here is that natural law governs health and disease, and the more we are aligned to natural law, the more likely we are to stay healthy. Is science not but our limited observation of natural law unfolding through investigation? Claude Bernard who contributed to the coining of the term "homeostasis" suggested that the delicate balance within the human is maintained through close and wise relation with the environment (nature).

When you work, you are a flute through whose heart the whispering of the hours turns to mu. This is in keeping with the observations of Hippocrates and Epictetus who mentioned that the physician is a servant of "the art" (natural law) and we must guide our patients toward this.

A practitioner should be knowledgeable, but that knowledge is vain if he/she does not put it into practice. And work is futile if it is not done with love, dedication, and surrender. When the health care practitioner works with empathy and compassion, it would not only result in positive outcomes for the patient but also improve professional satisfaction. Nothing in nature takes without giving, so a physician must give selflessly of himself. Gibran calls for "work with love" and defines it in poetic terms:

"And all knowledge is vain save when there is work,

And all work is empty save when there is love;

And when you work with love you bind yourself to yourself, and to one another, and to God."

On Work: Ch. 7, p. 39

Gibran then pointedly asks his readers:

"And what is to work with love?"

On Work: Ch. 7, p. 39

The Prophet replies to the ploughman:

"It is to weave the cloth with threads drawn from your heart, even as if your beloved were to wear that cloth.

It is to build a house with affection, even as if your

beloved were to dwell in that house.

It is to sow seeds with tenderness and reap the harvest with joy, even as if your beloved were to eat the fruit."

On Work: Ch. 7, p. 39

A century after he wrote the book, Gibran seems to speak directly to us. Would the patient-provider interaction, management plan, and outcomes not be significantly better if the provider treats the patient with the same care as he/she would for a loved one?

He is soft yet firm: in no unclear language, Gibran makes it clear that we should work with love, and not distaste. The diabetes care professional must internalize this love for our profession, and empathy for patients, in our daily practice.

"Work is love made visible. And if you cannot work with love but only with distaste, it is better that you should leave your work and sit at the gate of the temple and take alms of those who work with joy.

For if you bake bread with indifference, you bake a bitter bread that feeds but half man's hunger."

On Work: Ch. 7, p. 41

\section{Personal Ethics}

While significant progress is being made in the pharmacologic management of diabetes, it is imperative that diabetes care professionals remain rooted in ethical practice. Beneficence and nonmaleficence form the two core components of biomedical ethics in modern medicine. Gibran muses that it is our responsibility to share our knowledge and expertise to promote good health and well-being of others:

"And there are those who give and know not pain in giving, nor do they seek joy, nor give with mindfulness of virtue."

On Giving: Ch. 5, p. 28

Medicine has always been regarded as a noble profession through civilizations and in all cultures. The Prophet reminds us of our "greater calling" and purpose:

"Through the hands of such as these God speaks, and from behind their eyes He smiles upon the earth." On Giving: Ch. 5, p. 31

Physician burnout and compassion fatigue is well documented among diabetes care providers. But when the provider finds purpose in his/her work, it is not without its rewards for the diabetes care practitioner, for it is associated with greater compassion satisfaction and enhanced professional quality of life. When a physician works more toward a higher ideal (unselfish) rather than a short-term incentive (selfish), his energy and inspiration improves. Fatigue can be a sign of personalization of work and ego attachment.

"There are those who give with joy, and that joy is their reward."

On Giving: Ch. 5, p. 28

Keeping in mind, the dynamics of modern economies, he counsels moderation in financial dealings, as well as in lifestyle. These words attain greater relevance in today's medical care ecosystem, characterized by mistrust and misunderstanding between patients and physicians:

"Yet unless the exchange be in love and kindly justice, it will but lead some to greed and others to hunger." On Buying and Selling: Ch. 11, p. 52

\section{Person-Centered Care}

Biomedical ethics also encompass the principle of justice and autonomy. Effective delivery of health care requires a partnership between the provider and the patient, rather than a paternalistic approach. Understandably, current diabetes practice focuses on person-centered care, as well as informed decision making. Gibran seems to anticipate this philosophy, when he speaks to us of an ideal teacher, and the need to respect each other's attitudes and wishes. Chapter 18, "On Teaching," reports a conversation with a teacher:

"If he [the teacher] is indeed wise he does not bid you enter the house of wisdom, but rather leads you to the threshold of your own mind." On Teaching: Ch. 18, p. 80

The modern diabetes care professional functions not only as a medical care provider but also as a teacher and guide. 
True education is inculcating the ability to critically think and become self-sufficient. In this role, he/she often struggles to strike a balance between his/her knowledge of disease and the patient's perception of the same. It is imperative for the practitioner to gently direct and motivate the patient toward making appropriate lifestyle and therapeutic choices. However, much he/she may want the patient to behave in an ideal manner; it must be remembered that the perceptions of every individual are determined by a multitude of factors and in keeping with current science advocating individualized diabetes care:

As Gibran writes:

"For the vision of one man lends not its wings to another man."

On Teaching: Ch. 18, p. 81

"Your children are not your children.

And though they are with you, yet they belong not to you.

You may give them your love but not your thoughts.

For they have their own thoughts."

On Children: Ch. 4, p. 23

\section{Clinical Approach}

Diabetes care is becoming more and more complex as our understanding of this disorder increases. There are several consensus statements, algorithms, and expert opinions to guide the diabetes practitioner. They no doubt provide guidance for the practitioners, but they are not rule books to abide by and the clinician needs to be aware of this. As Gibran suggests:

"You delight in laying down laws, Yet you delight more in breaking them."

"But to whom life is a rock, and the law is a chisel with which they would carve it in their own likeness?"

"What shall I say of these, save that they too stand in the sunlight, but with their backs to the sun?"

On Laws: Ch. 13, p. 65

The Prophet beckons us to maintain concordance between theoretical knowledge and practical clinical sense. The ideal diabetes professional is one who achieves concordance between understanding of pathophysiology and prescription of therapy, as well as between his thoughts on one hand, and words and action, on the other.

"Who can separate his faith from his actions, or his belief from his occupation?"

On Religion: Ch. 26, p. 108

Today's diabetes management strategies focus on cardiovascular and other long-term outcomes, and rightly so. Previous metabolic health, however, has a strong bearing upon long-term outcomes; this concept is termed metabolic karma or metabolic memory. Gibran immortalized these scientific truths in a beautiful verse:

"And let today embrace the past with remembrance, and the future with longing."

On Time: Ch. 21, p. 89

Clinical practice should take an individual's past medical history into account, while planning interventions that aim for favorable future long-term outcomes. The future is a continuation of the past, modified by the present. Present actions lead to future effects. If present action is perfect, the future effect is successful.

\section{Scope for Improvement}

Diabetes care is a dynamic and evolving field, ever-changing, and ever-expanding. New understanding of pathophysiology has led to introduction of several new pharmacologic approaches. Simultaneously, old dogmas such as those related to the use of metformin are being broken. There is always scope for improvement, and Gibran tries to instill the dynamic nature of truth in his readers:

"Yet this we ask ere you leave us, that you speak to us and give us of your truth"

Seeress Almitra to the Prophet: Ch. 1, p. 11

Say not, "I have found the truth," but rather, "I have found a truth."

On Self-Knowledge: Ch. 17, p. 79

\section{The Person with Diabetes}

The Prophet speaks not only to the diabetes care professional but to individuals living with diabetes. They may do well to heed his advice, which speaks for a balanced life, trustful adherence to physician-led care, and maintaining emotional equipoise while coping with the stress of chronic disease.

\section{Health Care-Related Behavior}

Gibran is liberal in his advice, and we quote these verses for the patient with a philosophical taste. He emphasizes the importance of maintaining calm and tranquility and trust in the healer:

"Therefore, trust the physician, and drink his remedy in silence and tranquility;

For his hand, though heavy and hard, is guided by the tender hand of the Unseen"

On Pain: Ch. 16, p. 77

The patients would do well to gladly accept the advice of his care provider and attempt to understand that the aim of management is not just immediate symptom control but long-term health. The diabetes care professional is like an archer who aims that the arrow of good health maintains a swift and long-term trajectory:

"The archer sees the mark upon the path of the infinite, and He bends you with His might that His arrows may go swift and far.

Let your bending in the archer's hand be for gladness;

For even as He loves the arrow that flies, so He loves also the bow that is stable"

On Children: Ch. 4, p. 24

There is a great need for stability and continuity in medical care, and efforts need to be made by both provider as well as the patient. 


\section{Self-Care}

The Prophet does not neglect key aspects of self-care that are very relevant to self-management in diabetes. Indeed, the success of any diabetes management plan rests on the patient himself/herself:

"It is the bitter potion by which the physician within you heals your sick self"

On Pain: Ch. 6, p. 77

Gibran focuses on healthy eating, parsimonious lifestyle, and stress management:

"But since you must ... eat, ... let it then be an act of worship"

On Eating and Drinking: Ch. 6, p. 35

"And when you crush an apple with your teeth, say to it in your heart,"

"Your seeds shall live in my body... And together we shall rejoice through all the seasons"

On Pain: Ch. 6, p. 35

Perhaps, Gibran encourages outdoor activity as an essential part of healthy life. In the following verse, he glorifies the life-giving or salutogenic properties of sunlight and air:

"For the breath of life is in the sunlight and the hand of life is in the wind"

On Clothes Ch. 10, p. 50

\section{Diabetes Distress}

A certain amount of distress is inevitably felt by individuals living with diabetes and/or its complications. However, Gibran emphasizes that pain awakens us to greater understanding. Persons with diabetes should use this opportunity to improve their lives:

"Your pain is the breaking of the shell that encloses your understanding."

On Pain: Ch. 16, p. 74

Even in individuals who have developed complications, there is plenty in life to rejoice over. As The Prophet expounds, an individual should not become overly focused on pain and suffering and understand the fleeting nature of both sorrow and joy:

"And you would accept the seasons of your heart, even as you have always accepted the seasons that pass over your fields.

And you watch with serenity through the winters of your grief.

Much of your pain is self-chosen." On Pain: Ch. 16, pp. 74-77

An equanimous and balanced approach to emotions helps manage the vagaries of life in a stress-free manner. This has been stressed by Gibran:

$$
\begin{gathered}
\text { "But I say unto you, they [joy and sorrow] are } \\
\text { inseparable. }
\end{gathered}
$$

Together they come, and when one sits alone with you at your board, remember that the other is asleep upon your bed"

On Joy and Sorrow: Ch. 8, p. 43

\section{Team-Work and the Society}

Diabetes management is team work. Diabetes and persons with diabetes are inseparable. So too are diabetes care providers and persons living with diabetes. A relationship characterized by reciprocal respect, equipoise in dealing, and shared decision making is conducive for the health of all stakeholders:

"Go to your fields and your gardens, and you shall learn that it is the pleasure of the bee to gather honey from the flower.

But is it also the pleasure of the flower to yield its honey to the bee. For to the bee, a flower is a fountain of life. And to the flower, a bee is a messenger of love. And to both, bee and flower, the giving and receiving of pleasure is a need and an ecstasy."

"People ... be in your pleasures like the flowers and the bees"

On Pleasure: Ch. 24, p. 103

Optimal diabetes care, however, is about teamwork. The society needs to come together and join hands to overcome the diabetes pandemic. This is reflected in the following verses:

"Like a procession you walk together towards your god-self."

The Farewell: Ch. 28

"You are the way and the way farers"

On Crime and Punishment: Ch. 11, p. 59

\section{Summary}

Diabetes care is a never-ending journey, in which there are bound to be ups and downs. Outcomes may not always be what we desire. This should not stop us, however, from working toward them. As we travel on the road to diabetes care, we need to do our best.

We leave our readers with these thoughts, immortalized in The Prophet's words:

"You are good when you walk to your goal firmly and with bold steps."

"Yet you are not evil when you go thither limping, Even those who limp go not backward"

On Good and Evil: Ch. 22, p. 92

During this journey, we must remain humble and strive to improve ourselves in every possible manner:

"We must understand that there is no single teacher, and no single answer."

"Was it I who spoke? Was I not also a listener?"

The Farewell: Ch. 28, p. 117

"Wise men have come to you to give you of their wisdom. I came to take of your wisdom."

Say not, I have found the truth, but rather, I have found a truth.

On Self-Knowledge: Ch. 17, p. 79

If we are able to understand and internalize these truths of life, Gibran's The Prophet will have served its purpose. 
Conflict of Interest

None declared.

\section{Acknowledgments}

The authors acknowledge the inspiration and guidance we have received from Dr. Satya Sawant, Hisar, India, and Bharti Kalra, Karnal, India, in understanding the philosophy of The Prophet.

\section{Reference}

1 Gibran K. The Prophet. Mumbai, India: Wilco Publishing House; 2016 